\title{
Comparative study of bone regeneration using fibrin sealant with xenograft in rabbit sinus: pilot study
}

Won-Hyuk Choi ${ }^{1,2+}$, Yong-Deok Kim ${ }^{1,3+}$, Jae-Min Song ${ }^{1,24^{*}}$ and Sang-Hun Shin ${ }^{1,3^{*}}$ (D)

\begin{abstract}
Background: Stability of the grafted bone volume is one of the important factors to the success of alveolar bone grafts. For this, platelet-rich plasma (PRP) or fibrin sealant is mixed with the bone graft material. Bio-Oss ${ }^{\varpi}$ is a protein-free bovine mineral commonly used in bone graft procedures. The grafting particles are commonly combined with a standard fibrin sealant $\left(\right.$ Tissee $\left.^{\circledR}\right)$ to fabricate a plastic implantable product. The purpose of this experiment was to evaluate the efficacy of fibrin sealant $\left(\right.$ Tissee $\left.^{\oplus}\right)$ in bone regeneration performance in a rabbit maxillary sinus model.
\end{abstract}

Methods: A total of five $3.5 \mathrm{~kg}$ weight New Zealand white rabbits were used for the study. After elevating the sinus membrane in both maxillary sinus cavities, Bio-Oss ${ }^{\oplus}$ mixed with normal saline (group 1) was filled into the right side, and Tissee $^{\oplus}$ mixed Bio-Oss ${ }^{\oplus}$ (group 2) was inserted into the other side. The bone mineral density and bone volume were analyzed with microscopic computed tomography (micro-CT) and histomorphometric 12 weeks after application.

Results: Histologically, new bone formation rate was $14.8 \%$, and grafted bone rate was $70.5 \%$ in group 1. In group 2 , they were $18.5 \%$ and $60.4 \%$, respectively. According to micro-CT analysis, bone mineral density $\left(\mathrm{mg} / \mathrm{cm}^{3}, \mathrm{BMD}\right)$ was $2.5 \%$ larger in group 1.

Conclusions: The findings from this study suggest that, although the difference in the bone formation between group 1 and group 2 appears to be insignificant, group 2 had an advantage in using smaller amount of bone substances to achieve the reliable bone formation.

Keywords: Animal models, Xenograft, Bone graft, Maxillary sinus, Fibrin sealant

\section{Background}

In the edentulous state of maxilla, especially posterior area, bone grafting of the maxillary sinus is a critical process for implantation [1]. Numerous maxillary sinuslifting methods have been reported to manage severe atrophies in the maxillary posterior area [2-5]. One of the critical problems that surgeons face is to prepare efficient grafting materials for the cavities under lifted sinus

\footnotetext{
* Correspondence: songjm@pusan.ac.kr; ssh8080@pusan.ac.kr

${ }^{+}$Won-Hyuk Choi and Yong-Deok Kim contributed equally to this work. 'Department of Oral and maxillofacial surgery, School of dentistry, Pusan National University, Yangsan 50612, Republic of Korea

Full list of author information is available at the end of the article
}

membrane. Bio-Oss ${ }^{\oplus}$ (Geistlich Biomaterials, Wolhusen, Switzerland) is a protein-free bovine bone product very often used for lifting sinus [3, 6-8]. The materials can be mixed with normal saline or generalized fibrin (Tisseel ${ }^{\circ}$ ) to fabricate plastic materials. The fibrin sealant helps prevent Bio-Oss ${ }^{\bullet}$ particles from scattering. This then ultimately will require less grafting materials to maintain the spaces under lifted sinuses. However, controversies on efficacy of fibrin still exists saying that graft materials with or without Tisseel $^{\circ}$ yield the similar performance in new bone formation [9-14]. Some studies have shown that adding fibrin to the graft material does not have any positive effects on bone formation [15-20]. These

\section{Springer Open}

(0) The Author(s). 2021 Open Access This article is licensed under a Creative Commons Attribution 4.0 International License, which permits use, sharing, adaptation, distribution and reproduction in any medium or format, as long as you give appropriate credit to the original author(s) and the source, provide a link to the Creative Commons licence, and indicate if changes were made. The images or other third party material in this article are included in the article's Creative Commons licence, unless indicated otherwise in a credit line to the material. If material is not included in the article's Creative Commons licence and your intended use is not permitted by statutory regulation or exceeds the permitted use, you will need to obtain permission directly from the copyright holder. To view a copy of this licence, visit http://creativecommons.org/licenses/by/4.0/. 
controversial opinions about the efficacy of fibrin materials have provoked a comparative study on the bone regeneration using normal saline or Tisseel ${ }^{\circ}$. The purpose of this animal study was to compare the histomorphological and histological findings of protein-free bovine mineral mixed with normal saline and Tisseel $^{\circ}$ in a rabbit maxillary sinus model.

\section{Methods}

\section{Animal models}

Five New Zealand white rabbits $(3.5 \mathrm{~kg})$ were used in this study. The protocol was approved by the Institutional Animal Care and Use Committee.

\section{Surgical procedure}

All surgical procedures were performed under general anesthesia. A 3-cm vertical incision was given on the median nasal dorsum of rabbit, and the periosteum was elevated. Then, $10-\mathrm{mm}^{2}$ bony window was created in both sinus with a round bur. After lifting the floor of the sinus membrane, the cavities below each sinus membrane was divided into the next two groups according to the materials filled: group 1 , Bio-Oss ${ }^{\oplus}$ mixed with normal saline, or group 2, Bio-Oss ${ }^{\circ}$ mixed with Tisseel $^{\circledR}$ (Immuno AG, Vienna, Austria). The normal saline and Tisseel $^{\circ}$ were mixed with the same volume of Bio-Oss ${ }^{\circ}$ (Fig. 1).

\section{Sample preparation and histomorphometry}

Animals were sacrificed 12 weeks after the surgery, and bone blocks were excised. Resected bone specimens were fixed in $10 \%$ buffered formalin and embedded in methyl-methacrylate resin. The blocks were cut longitudinally through the middle plane of the implants. Histological sections $(40 \mathrm{~mm})$ were prepared using a cuttinggrinding method and were stained with Masson's trichrome stain and hematoxylin and eosin stain. The bone mineral density and bone volume were analyzed with micro-CT and histomorphometrics.

The histomorphometry was analyzed by the same inspector using an image analysis system that measures the proportion of newly deposited bone. The system consists of an infinitely calibrated optical microscope, a high-resolution digital camera, an image capture device, and a computer-based image processor for measuring tissue morphology. The Aperio Technologies Scanscope CS system is useful for calculating new bone formation areas on HEstained slides. The calculation, involving just the drawing of the newly formed bone outlines, is easily done. To calculate the new bone formation area, 3 sites were randomly selected for each slide, the photographs of which were $1 \mathrm{~mm} \times 1 \mathrm{~mm}$. Images of newly formed bones were identified by the color given in each image. They are digitized and sent to a

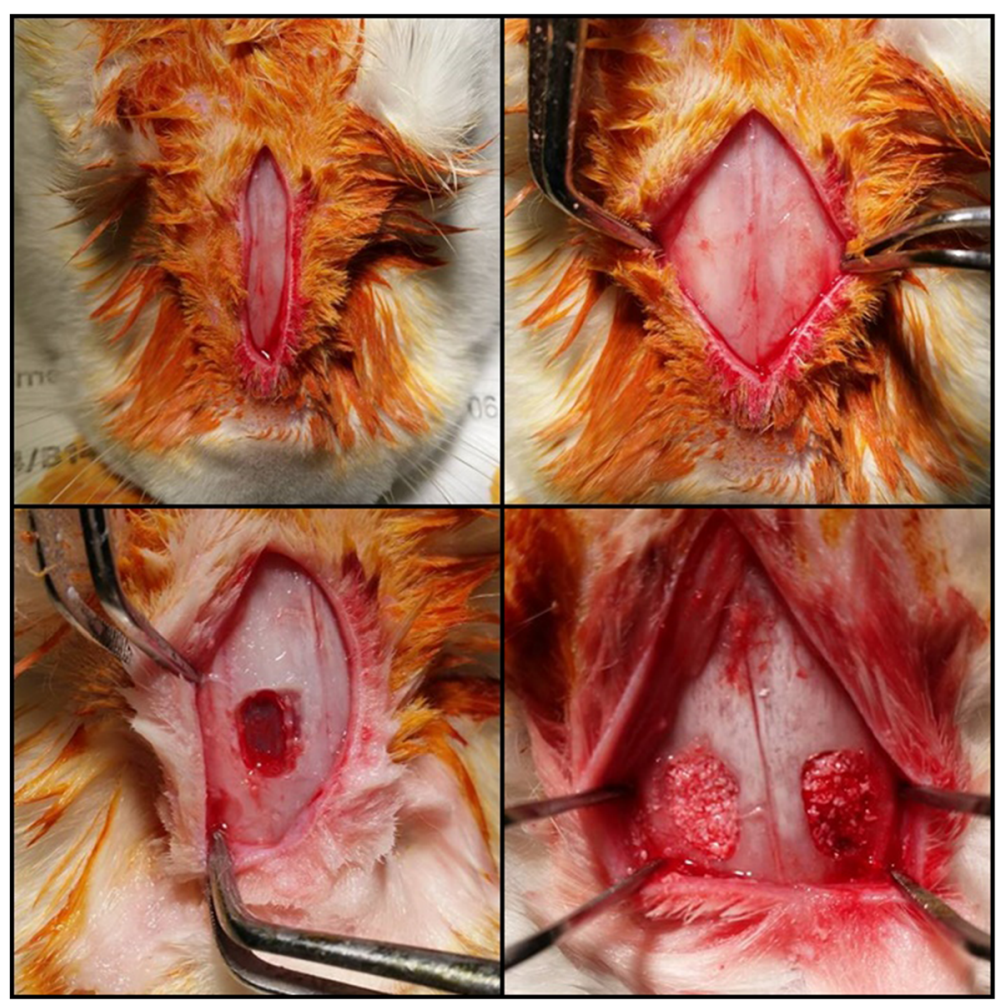

Fig. 1 Clinical photographs of surgical procedures. G 1, group 1, Bio-Oss ${ }^{\oplus}$; G 2, group 2, Bio-Oss ${ }^{\circledast}$ mixed with Tisseel ${ }^{\otimes}$ 
computer for image processing, and a formula is used to analyze the quantity percentage of the total area of the defect:

$$
\begin{aligned}
& \text { A new bone formation ratio }(\%) \\
& =\frac{\text { New bone in defect site }}{\text { Total defect site }} \times 100
\end{aligned}
$$

\section{Results}

\section{Gross observations}

All animals recovered from surgery and healed without any complications until the end of the experiment. During the operation, animals showed no clinical signs of sinusitis. Post-operative healing was within normal range in all cases (Fig. 2).

\section{Histologic and histomophometric findings}

Twelve weeks after the sinus lift, an examination of the bone specimens showed that in the Tisseel $^{\circ}$ mixed Bio$\mathrm{Oss}^{\circ}$ site the grafted particles were surrounded by a layer of newly formed bone (Fig. 3). The new bone formation rate was $18.5 \%$. The new bone surrounding the grafted particles was also surrounded by fibrovascular tissue (Fig. 3). In the normal saline mixed Bio-Oss ${ }^{\circ}$ site, the grafted particles were also surrounded by new bone but smaller amounts of new bone (Fig. 3). The new bone formation rate was $14.8 \%$. In the contrary, the amount of grafted bone rate was larger in the normal saline mixed Bio-Oss ${ }^{\circ}$ site compared to the Tisseel $^{\circ}$ mixed Bio$\mathrm{Oss}^{\oplus}$ site (70.5\% vs. $\left.60.4 \%\right)$ (Table 1$)$. In the composition bone volume measurement through micro-CT analysis (Fig. 4), group 2 showed that the amount of graft used was smaller than group 1 (Table 2).

\section{Discussion}

Sinus-lifting surgery is a routinely performed technique for increasing the height of the pneumatized posterior maxilla. Sinus floor augmentation is considered a highly successful procedure, but complications during or after surgery can still occur $[21,22]$. The most frequent surgical complication is perforation of Schneiderian membrane, with reported incidence between 10 and 55\% [23, 24]. Schneiderian membrane at the base of this upper jaw may be perforated for anatomical reasons, surgical risk factors, or pathophysiological factors [25]. The underside of the membranes is a unique space where graft materials are placed between hard and soft tissues, and constant respiratory air pressure exists, making it difficult to maintain volume stability. The perforation of membrane which can occur during surgery or postoperatively is a risk factor that can cause postoperative acute and chronic sinusitis due to particulate materials. To

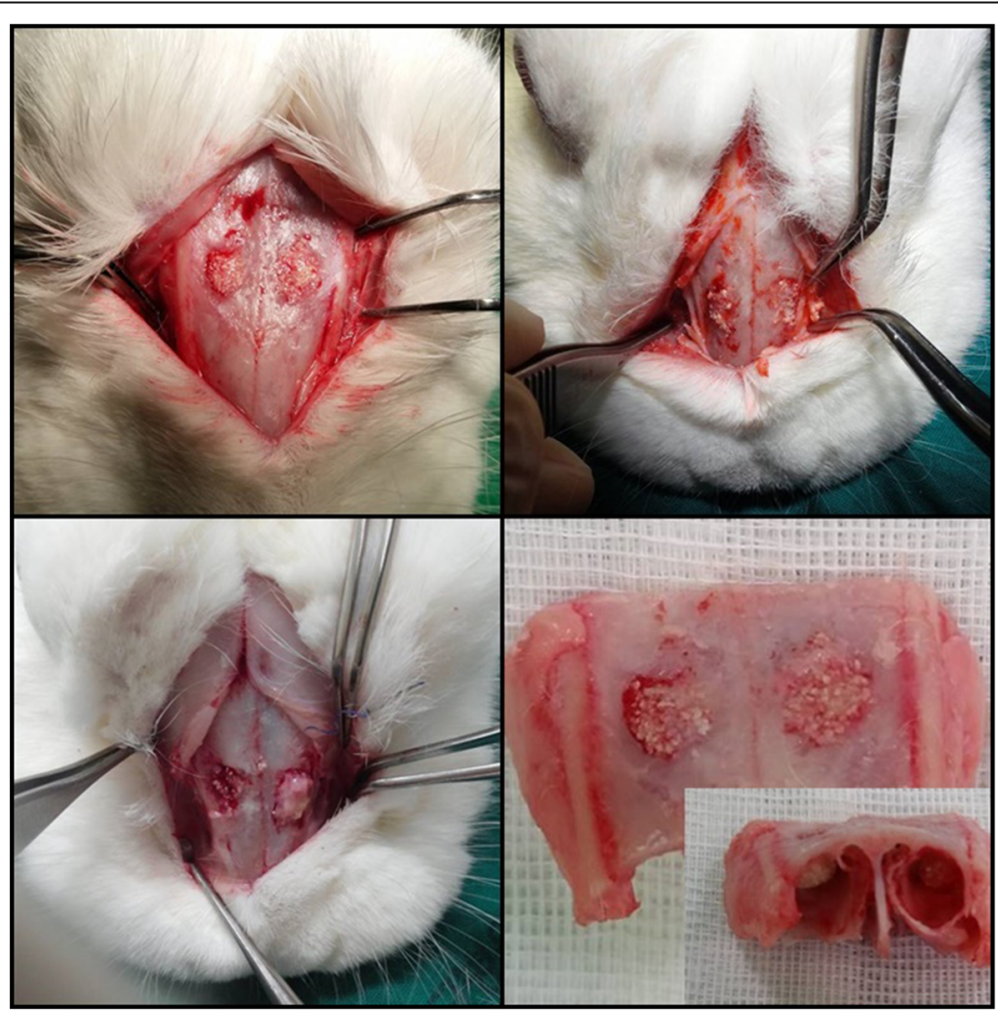

Fig. 2 Photograph of experiment after sampling. G 1, group 1, Bio-Oss ${ }^{\oplus}$; G 2, group 2, Bio-Oss ${ }^{\oplus}$ mixed with Tisseel ${ }^{\circledR}$ 


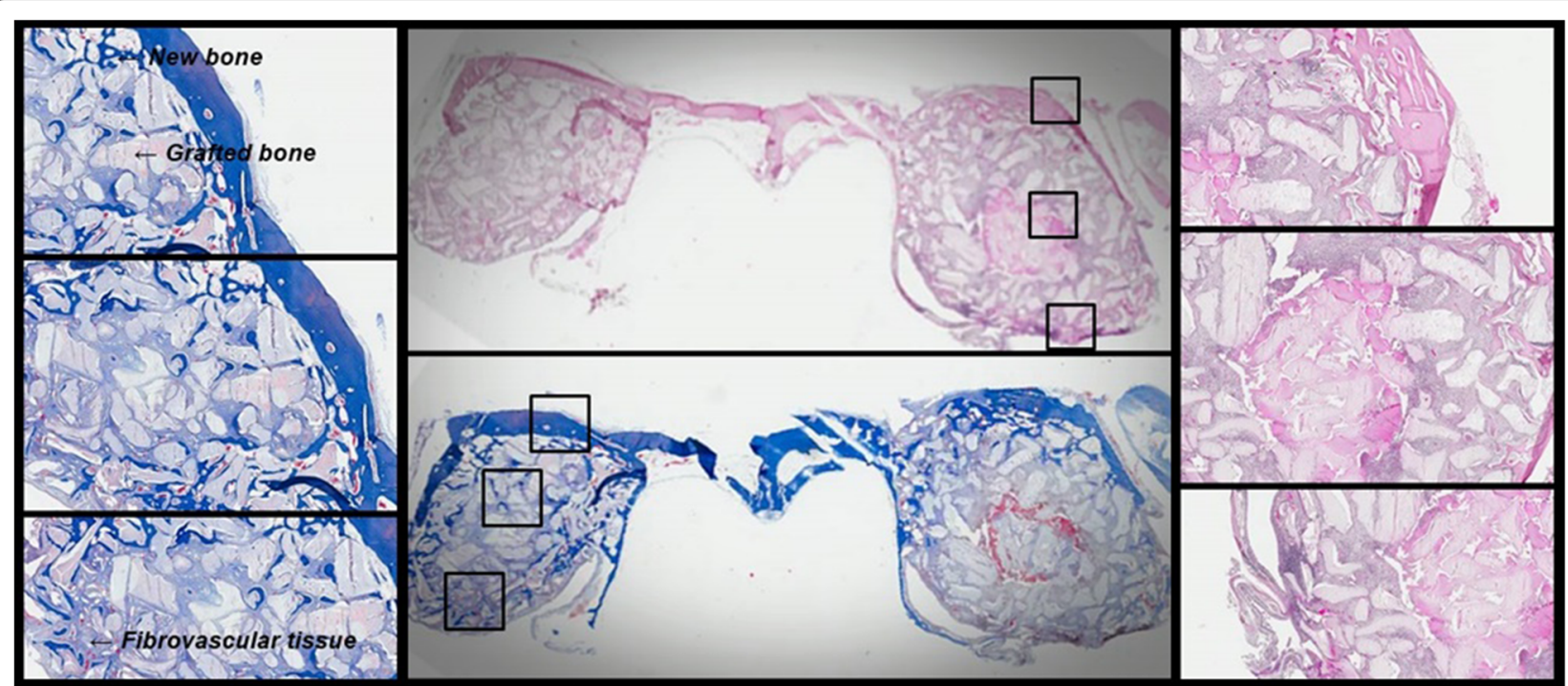

Fig. 3 Photomicrograph shows grafted region after 12 weeks. a Masson's trichrome stain $\times 100$. b Overall view. $\mathbf{c}$ Hematoxylin and eosin stain $\times$ 100. G 1, group 1, Bio-Oss ${ }^{\oplus}$; G 2, group 2, Bio-Oss ${ }^{\oplus}$ mixed with Tisseel ${ }^{\circledast}$

prevent this, the grafting material should be confined to the space underneath the membrane. Fabrication of grafting bone particles may involve PRP that are collected from the patient's blood or Tisseel ${ }^{\circ}$, a commercial product. Drawing blood samples to collect PRP can cause discomfort to the patient and thus it can negatively affect rapport between the surgeon and a patient.

The results indicate that the incorporation of fibrin sealant with the bone graft materials showed insignificant differences. The rate of new bone formation was slightly higher than control groups, indicating that the materials needed for the lifting reduced in amount. In group 1, the bone density measured was high. In the case of fibrovascular tissue, it was higher in group 2.

In the case of Bio-Oss ${ }^{\circ}$ mixed with Tisseel $^{\circ}$ for maxillary sinus lift, bone formation in group 2 was higher than group 1. Group 2 showed some signs of inflammation. This may have caused Tisseel $^{\circ}$ to impair the initial vascularization of the biomaterial and consequently limited the bone growth to the implant site. The reason for this may be due to the accumulation of granulation tissue with decomposing collagen tissue on the heavily damaged site. The results obtained from this study are similar to those from previously conducted animal experiments. Carmagnola et al. showed that the integration ratio between Bio-Oss ${ }^{\circ}$ and bone surface was significantly higher in defects treated with Bio-Oss ${ }^{\circ}$ mixed with Tisseel $^{\oplus}[15,16]$. Luht et al. studied bone formation and local blood flow over a graft containing fibrin sealant mixed with iliac bone in standardized defects in dog's tibia [26]. This study indicated that the fibrin sealant did not work to encourage the formation of new bones and fibrous capsules formed around grafted particles.

Table 1 Histologic analysis of groups 1 and 2

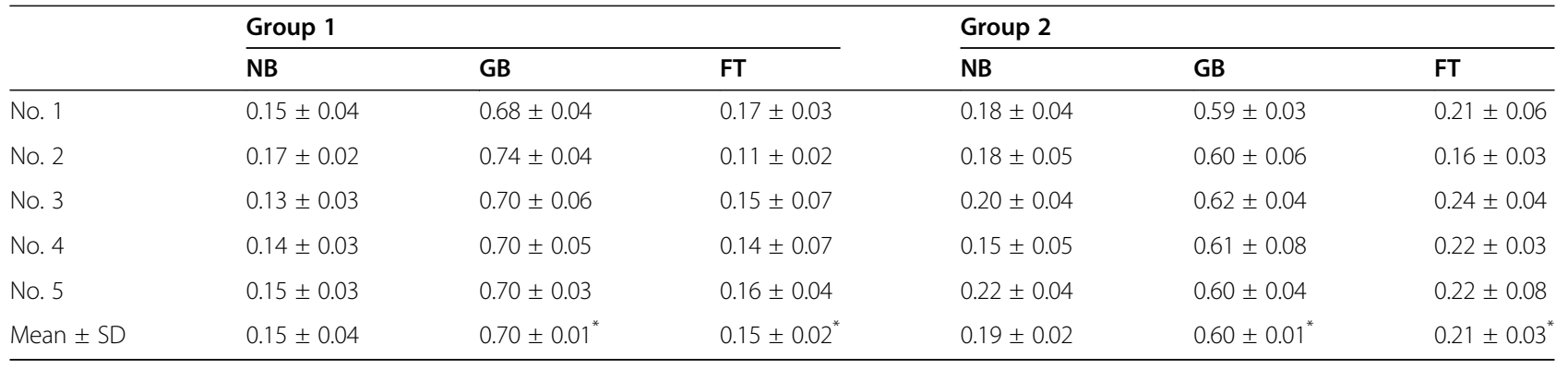

$N B$ new bone, $G B$ grafted bone, $F T$ fibrovascular tissue

Group 1 Bio-Oss $^{\oplus}$, group 2 Bio-Oss $^{\oplus}$ mixed with Tisseel ${ }^{\bullet}$

${ }^{*} P<0.05$ 


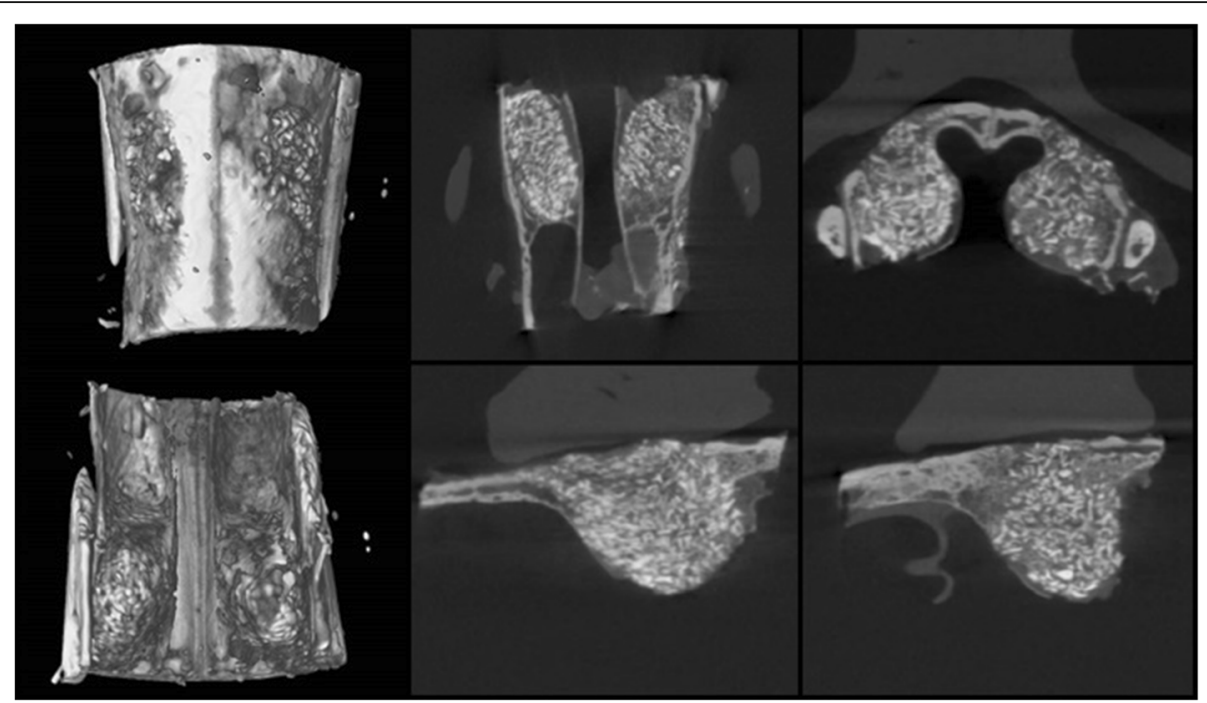

Fig. 4 Micro-CT analysis. a Three-dimensional image. b Axial view. c Coronal view. d Right sagittal view. e Left sagittal view. G 1, group 1, BioOss $^{\oplus} ;$ G 2, group 2, Bio-Oss ${ }^{\oplus}$ mixed with Tisseel $^{\oplus}$

On the other hand, the grafted bone volume was smaller in using Tisseel $^{-}$mixed site. This means that even if only a small amount of graft material is used in the group using Tisseel $^{\circ}$, the success rate of bone transplantation is the same as that of the site where normal saline was mixed and transplanted. It was found that the difference in BMD by our micro-CT analysis was not significantly different from the case of using normal saline. The volume of the implant has to do with the time when new bones are formed. The time taken for the formation of new bone is affected by the amount of grafted bone. Consequently, the amount of biomaterial required for a defect should be carefully measured and decided. The fact that the mixed compounds have a positive effect on the handling and adhesion of skeletal defect walls has been pointed out before [27].
These physical and biological properties are obviously helpful for surgeons. For this reason, the results of this study suggest that Tisseel $^{\circ}$ can serve as a delivery system for grafting particles in the sinus floor elevation, although there are clinical limitations such as the time of melting in use and relatively high cost.

\section{Conclusions}

This experiment was a pilot experiment to examine the advantages and disadvantages of the use of Tisseel ${ }^{\circledR}$ when the maxillary sinus elevation was performed using Bio-Oss ${ }^{\circledR}$ mixed with normal saline and Tisseel ${ }^{\circledR}$. Through this experiment, it can be speculated that the use of Tisseel ${ }^{\circledR}$ will reduce the amount of bone to be transplanted, and as a result, the bone healing period for dental implant placement after surgery will ultimately be reduced.

Table 2 Volume measurements in groups 1 and 2 using micro-CT

\begin{tabular}{|c|c|c|c|c|c|c|}
\hline & \multicolumn{3}{|l|}{ Group 1} & \multicolumn{3}{|l|}{ Group 2} \\
\hline & $\mathrm{TV}\left(\mathrm{mm}^{3}\right)$ & BV $\left(\mathrm{mm}^{3}\right)$ & BV/TV (\%) & $\mathrm{TV}\left(\mathrm{mm}^{3}\right)$ & BV $\left(\mathrm{mm}^{3}\right)$ & BV/TV (\%) \\
\hline No. 1 & 33.84 & 32.31 & 95.48 & 43.27 & 34.60 & 79.96 \\
\hline No. 2 & 87.67 & 82.81 & 94.46 & 89.01 & 70.26 & 78.93 \\
\hline No. 3 & 48.67 & 47.15 & 96.88 & 56.09 & 45.55 & 81.21 \\
\hline No. 4 & 52.59 & 51.27 & 97.49 & 36.06 & 29.03 & 80.50 \\
\hline No. 5 & 88.61 & 87.09 & 98.29 & 77.12 & 64.21 & 83.26 \\
\hline Mean \pm SD & $62.27 \pm 24.62$ & $60.12 \pm 23.78$ & $96.51 \pm 1.54^{*}$ & $60.31 \pm 22.37$ & $48.73 \pm 18.03$ & $80.77 \pm 1.62^{*}$ \\
\hline
\end{tabular}

$T V$ total augmented volume, $B V$ volume of bone

Group 1 Bio-Oss $^{\oplus}$, group 2 Bio-Oss $^{\oplus}$ mixed with Tisseel $^{\circledast}$

${ }^{*} P<0.05$ 


\section{Abbreviations}

PRP: Platelet-rich plasma; micro-CT: Microscopic computed tomography; BMD: Bone mineral density

\section{Acknowledgements}

None

\section{Authors' contributions}

WHC and JMS made contributions to the conception of the report and carried out the experiment. WHC and JMS carried out the experiment. YDK and SHS participated in the collection of data and drafting of the manuscript. All authors read and approved the final manuscript.

\section{Funding}

This work was supported by a 2-year research grant of Pusan National University.

\section{Availability of data and materials}

Not applicable.

\section{Ethics approval and consent to participate}

The protocol was approved by the Institutional Animal Care and Use Committee, Pusan National University Yangsan Hospital, Korea, and the approval number is PNUYH-2014-025

\section{Consent for publication}

This manuscript does not contain any individual person's identifier (including individual details, images, or videos).

\section{Competing interests}

The authors declare that they have no competing interests.

\section{Author details}

${ }^{1}$ Department of Oral and maxillofacial surgery, School of dentistry, Pusan National University, Yangsan 50612, Republic of Korea. ${ }^{2}$ Department of Oral and maxillofacial surgery, Pusan National University Hospital, Pusan 49241, Republic of Korea. ${ }^{3}$ Dental and Life Science Institute \& Dental Research Institute, Pusan National University Dental Hospital, Yangsan 50612, Republic of Korea. ${ }^{4}$ Biomedical Research Institute, Pusan National University Hospital, Pusan 49241, Republic of Korea.

Received: 16 December 2020 Accepted: 3 January 2021 Published online: 10 February 2021

\section{References}

1. Kahnberg KE, Ekestubbe A, Grondahl K, Nilsson P, Hirsch JM (1999) Sinus lifting procedure. I. One-stage surgery with bone transplant and implants. Clin Oral Implants Res 12(5):479e487

2. Summers RB (1994) A new concept in maxillary implant surgery: the osteotome technique. Compendium 15(2):152e162

3. Wetzel AC, Stich H, Caffesse RG (1995) Bone apposition onto oral implants in the sinus area filled with different grafting materials. Clin Oral Implants Res 6(3):155e 163

4. Zitzmann NU, Schärer $P$ (1998) Sinus elevation procedures in the resorbed posterior maxilla. Oral Surg Oral Med Oral Pathol Oral Radiol 85(1):8e17

5. Hallman M, Sennerby L, Zetterqvist L, Lundgren S (2005) A 3-year prospective follow-up study of implant-supported fixed prostheses in patients subjected to maxillary sinus floor augmentation with an 80:20 mixture of deproteinized bovine bone and autogenous bone: clinical, radiographic and resonance frequency analysis. Int J Oral Maxillofac Surg 34(3):273e280

6. Hürzeler MB, Kirsch A, Ackermann KL, Quinones CR (1996) Reconstruction of the severely resorbed maxilla with dental implants in the augmented maxillary sinus: a 5-year clinical investigation. Int J Oral Maxillofac Implants 11(4):466e475

7. Haas R, Donath K, Födinger M, Watzek G (1998) Bone hydroxyapatite for maxillary sinus grafting: comparative histomorphometric findings in sheep. Clin Oral Implants Res 9(2):107e116

8. Valentini P, Abensur D, Densari D, Graziani JN, Hämmerle CHF (1998) Histological evaluation of Bio-Oss ${ }^{\circledast}$ in a 2-stage sinus floor elevation and implantation. Clin Oral Implants Res 9(1):59e64
9. Kim ES, Park EJ, Choung PH (2001) Platelet concentration and its effect on bone formation in calvarial defects: an experimental study in rabbits. J Prosthet Dent 86(4):428e433

10. Kim SG, Kim WK, Park JC, Kim HJ (2002) A comparative study of osseointegration of Avana implants in a demineralized freeze-dried bone alone or with platelet-rich plasma. J Oral Maxillofac Surg 60(9):1018e1025

11. Sanchez AR, Sheridan PJ, Kupp LI (2003) Is platelet-rich plasma the perfect enhancement factor? A current review. Int J Oral Maxillofac Implants 18(1): $93 e 103$

12. Saffarzadeh A, Gauthier O, Bilban M, BagotD'Arc M, Daculsi G (2009) Comparison of two bone substitute biomaterials consisting of a mixture of fibrin sealant $\left(\right.$ Tissee $\left.^{\oplus}\right)$ and MBCP ${ }^{\text {TM }}\left(\right.$ TricOs $\left.^{\oplus}\right)$ with an autograft in sinus lift surgery in sheep. Clin Oral Implants Res 20(10):1133e1139

13. Kim BJ, Kwon TK, Baek HS, Hwang DS, Kim CH, Chung IK et al (2012) A comparative study of the effectiveness of sinus bone grafting with recombinant human bone morphogenetic protein 2-coated tricalcium phosphate and platelet-rich fibrin mixed tricalcium phosphate in rabbits. Oral Surg Oral Med Oral Pathol Oral Radiol 113(5):583e592

14. Metzler P, von Wilmowsky C, Zimmermann R, Wiltfang J, Schlegel KA (2012) The effect of current used bone substitution materials and platelet-rich plasma on periosteal cells by ectopic site implantation: an in-vivo pilot study. J Craniomaxillofac Surg 40(5):409e415

15. Carmagnola D, Berglundh T, Araujo M, Albrektsson T, Lindhe J (2000) Bone healing around implants placed in a jaw defect augmented with Bio-Oss ${ }^{\oplus}$. An experimental study in dogs. J Clin Periodontol 27(11):799e805

16. Carmagnola D, Berglundh $T$, Lindhe J (2002) The effect of a fibrin glue on the integration of Bio-Oss ${ }^{\circledR}$ with bone tissue. J Clin Periodontol 29(5): $377 \mathrm{e} 383$

17. Jakse N, Tangl S, Gilli R, Berghold A, Lorenzoni M, Eskici A et al (2003) Influence of PRP on autogenous sinus grafts. Clin Oral Implants Res 14(5): $578 \mathrm{e} 583$

18. Grageda E, Lozada JL, Boyne PJ, Caplanis N, McMillan PJ (2005) Bone formation in the maxillary sinus by using platelet-rich plasma: an experimental study in sheep. J Oral Implantol 31(1):2e17

19. Kazakos K, Lyras DN, Thomaidis V, Agrogiannis G, Botaitis S, Drosos G et al (2011) Application of PRP gel alone or in combination with guided bone regeneration does not enhance bone healing process: an experimental study in rabbits. J Craniomaxillofac Surg 39(1):49e53

20. Zhang Y, Tangl S, Huber CD, Lin Y, Qju L, Rausch-Fan X (2012) Effects of Choikroun's platelet-rich fibrin on bone regeneration in combination with deproteinized bovine bone mineral in maxillary sinus augmentation: a histological and histomorphometric study. J Craniomaxillofac Surg 40(4): 321 e328

21. Danesh-Sani SA, Loomer PM, Wallace SS (2016) A comprehensive clinical review of maxillary sinus floor elevation: anatomy, techniques, biomaterials, and complications. Br J Oral Maxillofac Surg 54(7):724-730

22. Stacchi C, Andolsek F, Berton F, Perinetti G, Navarra CO, Di Lenarda R (2017) Intraoperative complications during sinus floor elevation with lateral approach: a systematic review. Int J Oral Maxillofac Implants 32(3):e107e118

23. Al-Dajani M (2016) Incidence, risk factors, and complications of Schneiderian membrane perforation in sinus lift surgery: a meta-analysis. Implant Dent 25(3):409-415

24. Schwarz L, Schiebel V, Hof M, Ulm C, Watzek G, Pommer B (2015) Risk factors of membrane perforation and postoperative complications in sinus floor elevation surgery: review of 407 augmentation procedures. J Oral Maxillofac Surg 73(7):1275-1282

25. Favero V, Lang NP, Canullo L, Urbizo Velez J, Bengazi F, Botticelli D (2016) Sinus floor elevation outcomes following perforation of the Schneiderian membrane. An experimental study in sheep. Clin Oral Implants Res 27(2): 233-240

26. Lucht U, Bünger C, Møller JT, Joyce F, Plenk H Jr (1986) Fibrin sealant in bone transplantation. No effects on blood flow and bone formation in dogs. Acta Orthop Scand 57(1):19-24

27. Le Guéhennec L, Layrolle P, Daculsi G (2004) A review of bioceramics and fibrin sealant. Eur Cell Mater 8(13):1e11

\section{Publisher's Note}

Springer Nature remains neutral with regard to jurisdictional claims in published maps and institutional affiliations. 